\title{
Residual Spray for the Control of Aedes Vectors in Dengue Outbreak Residential Areas
}

\author{
Nurulhusna Ab Hamid1*, Siti Nurfadhlina Mohd Noor1', Mitra Saadatian-Elahi², \\ Nur Rasyidah Isa1, Rohaiyu Md Rodzay1, Balqis Md Ruslan1, Topek Omar3, \\ Mohd Iqbal Mohd Norsham1, Noor Hasmiza Amanzuri', Nurliyana Abd Khalil1, \\ Izzah Farhah Zambari', Muhammad Anwar Mohd Kassim', Muhammad Khairi Kamarul Zaman', \\ Ainaa Mardia Bachtiar Effendi ${ }^{1}$, Afiq Ahnaf Hafisool ${ }^{1}$, Lee Teck Peng ${ }^{4}$, \\ Brian Poong4, Mustafakamal Ibrahim5, Nurul Ashikin Roslan5, Lee Han Lim¹

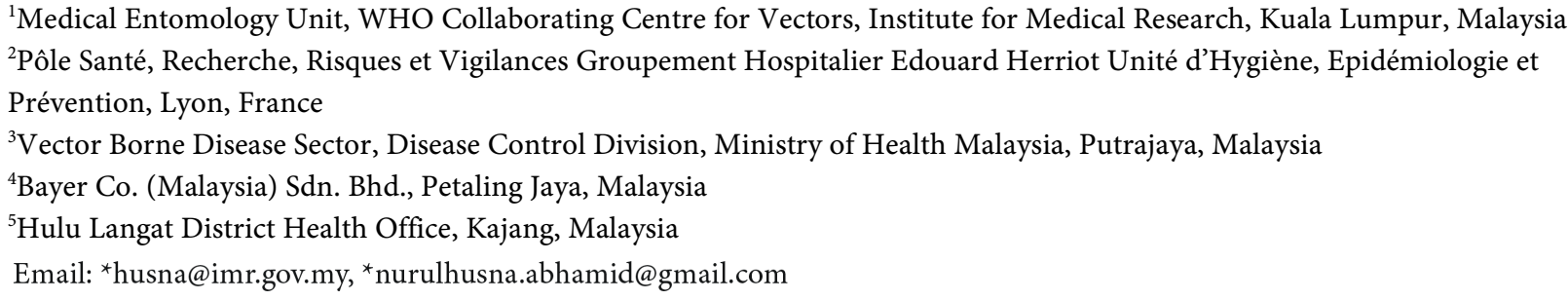

How to cite this paper: Hamid, N.A., Noor, S.N.M., Saadatian-Elahi, M., Isa, N.R., Rodzay, R.M., Ruslan, B.M., Omar, T., Norsham, M.I.M., Amanzuri, N.H., Khalil, N.A., Zambari, I.F., Kassim, M.A.M., Zaman, M.K.K., Effendi, A.M.B., Hafisool, A.A., Peng, L.T., Poong, B., Ibrahim, M., Roslan, N.A. and Lim, L.H. (2019) Residual Spray for the Control of Aedes Vectors in Dengue Outbreak Residential Areas. Advances in Entomology, 7, 105-123. https://doi.org/10.4236/ae.2019.74009

Received: August 5, 2019

Accepted: October 14, 2019

Published: October 17, 2019

Copyright $\odot 2019$ by author(s) and Scientific Research Publishing Inc. This work is licensed under the Creative Commons Attribution International License (CC BY 4.0).

http://creativecommons.org/licenses/by/4.0/

\begin{abstract}
The incidence of dengue in Malaysia has shown an increasing trend since the year 2000. Vector control is the primary approach for dengue control in Malaysia. There is an urgent need for new or modified approaches such as the residual spraying on the outer walls that can potentially last long enough to control the Aedes population, particularly in the outbreak-prone areas. In this field study, we conducted outdoor residual spraying (ORS) using a newly formulated polymer-enhanced suspension concentrate (SC-PE) of deltamethrin. The objectives of this study were to evaluate the efficacy of ORS using deltamethrin SC-PE and its effect on wild Aedes populations and to assess its residual bio-efficacy on painted cement walls against the pyrethroid-susceptible strains of laboratory-reared Aedes mosquitoes. Three rounds of spraying in a four-month cycle were conducted between 2014 and 2015 in four residential areas (low-rise and high-rise housing types) in Hulu Langat, Selangor. The bio-efficacy of the insecticide was evaluated by assessing its impact on vector population using ovitrap surveillance. Standard WHO wall deposit bioassay was adapted to determine bio-efficacy of deltamethrin, i.e. post 30 min knockdown and post $24 \mathrm{~h}$ mortality after exposure. During the treatment period, we observed significant reductions in the population of Ae. albopictus in the sprayed low-rise housing in both semi-indoor and outdoor environments, while in the high-rise housing, there was also a significant decline in $A e$. ae-
\end{abstract}


gypti population in the semi-indoor environment. The evaluation of the residual bio-efficacy of deltamethrin SC-PE against laboratory-reared Aedes mosquitoes showed that the insecticide lasted longer in the high-rise housing compared to the low-rise housing with $>80 \%$ mortality achieved continuously for 16 weeks. We provide initial evidence on residual efficacy of deltamethrin SC-PE in reducing Aedes population size in the low-rise and high-rise housing. Our results showed that ORS is a promising tool in the dengue vector control and like IRS in malaria control; it is a powerful and effective method if conducted correctly. However, large scale and well-designed studies with entomological and epidemiological endpoints are still warranted before its routine use in dengue control.

\section{Keywords}

Indoor Residual Spraying, Outdoor Residual Spraying, Aedes, Deltamethrin SC-PE, Dengue, Vector Control, Ovitrap Index, Malaysia

\section{Introduction}

Dengue is the predominant mosquito-borne disease in humans, caused by one of the four serotypes of dengue virus (DENV-1 - 4) that belongs to the genus Flavivirus. The virus is transmitted through the bite of an infected female of sympatric Aedes aegypti and Ae. albopictus. Dengue disease is endemic in more than 120 countries with the highest disease burden reported in Asia and Latin America [1] [2]. Within Asia, Malaysia ranked the third most affected country between the years 1991-2007 [3]. The incidence of dengue in Malaysia showed an escalating trend from 31.6 per 100,000 population in 2000 to 159.7 per 100,000 population in 2010 [4]. Dengue infection affected all ethnicities and gender with an observed predominance in males and Malays [4] [5].

In the absence of an effective and safe vaccine against the dengue virus, vector control remains as the primary approach for the prevention and control of dengue. Interruption of dengue transmission through vector control in the Caribbean, America, Cuba, and Singapore has resulted in a substantial reduction of the mosquito population and human cases of dengue [6] [7] [8] [9] [10]. Unfortunately, these success histories did not sustain and have failed to prevent dengue outbreaks due to several reasons, including inappropriate implementation, lack of sustainability over-time and reduced herd immunity [10] [11] [12] [13]. These are the compelling reasons for the continuation of research and development on new insecticides and tools for dengue control. At present, there is no consensus regarding the type of vector control approach that can bring the largest impact on dengue transmission for both epidemic situation and sustained management [14]. Hence, there is an urgent need for new or modified approaches such as the residual spraying on the outer walls that can potentially last long enough to control the Aedes population, especially in the outbreak areas. 
The integration of this modified approach as part of the Integrated Vector Management (IVM) may possess an unexploited potential for an effective dengue control effort if executed correctly.

Indoor residual spraying (IRS) involves the application of long-lasting chemical insecticides on the inner walls, eaves and ceiling of properties where the mosquitoes might encounter the insecticides while resting on these structures [15]. IRS was historically used as the primary tool in the Global Malaria Eradication Program (1955-1969), which has resulted in the total elimination of malaria in 37 out of 143 countries while reducing malaria burden in other countries [15] [16] [17] [18]. A few studies have shown that the IRS is a promising dengue control tool and has high efficiency in reducing the Aedes populations. The application of IRS using deltamethrin in Peruvian Amazon has appeared to produce $>80 \%$ mortalities in Ae aegypti in bioassay test for up to eight weeks post-spraying when applied on wood, unpainted wood and brick, and reduced adult index from 18.5 to 3.1, a month after the intervention [19]. Research in Merida, Mexico showed that treating inner house surfaces with bendiocarb has reduced Ae. aegypti infestation by $60 \%$ in three months period [20], and targeted IRS research in Cairns, Australia demonstrated that IRS along with location-based contact tracing had decreased the likelihood of dengue cases by $86 \%$ $96 \%$ in sprayed premises in comparison to unsprayed controls [21].

Deltamethrin polymer-enhanced suspension concentrate (SC-PE) (K-Othrine ${ }^{\circledR}$ Polyzone) is classified as pyrethroid and is one of the WHO recommended insecticides for IRS against malaria vector [22]. The insecticide is a new formulation of existing deltamethrin that has a prolonged residual effect through its property of the proprietary polymer. The polymer layer releases deltamethrin particle over an extended period and protects the deltamethrin particle from rainfall and abrasion. Consequently, less spraying applications are needed that in turn improve the cost-effectiveness of the residual spraying method and minimizing disruption to families. Recent studies in America and Tanzania have shown that deltamethrin SC-PE has superior performance than formerly developed deltamethrin water dispersible granule (WG) [23] [24] [25].

Here, we tested deltamethrin SC-PE in the outdoor residual spraying (ORS), a modified approach of an existing IRS method. The insecticide was applied to the outer walls of houses, instead of the indoor wall surfaces. This was done, in part, due to the lack of accessibility to houses and cooperation from the homeowners. ORS targets adult resting population where they may pick up the contact poison at a sufficient amount during resting to cause death. The behavior of Aedes mosquitoes resting on the walls is well established [26] [27]. The treated walls could also potentially act as barrier walls which prevent the mosquitoes from going inside houses for blood meals. We suggested that ORS is used as part of the national emergency response to a dengue outbreak. We applied deltamethrin SC-PE to the outer walls of terrace houses and apartment units at the application dosage of $30 \mathrm{mg} / \mathrm{m}^{2}$ in the residential areas in Hulu Langat district, Selangor. 
The objectives of this study were to evaluate the efficacy of ORS using deltamethrin SC-PE and its effect on wild Aedes populations and to assess its residual bio-efficacy on painted cement walls against the pyrethroid-susceptible strains of laboratory-reared Aedes mosquitoes.

\section{Materials and Methods}

\subsection{Study Site and Design}

This study was conducted in four residential neighbourhoods in Hulu Langat District, Selangor. The study sites were selected based on epidemiological and ovitrap surveys by the Health District Office that has classified these zones as dengue outbreak hotspots with high vector density of Aedes spp. ( $\geq 10 \%$ ovitrap index threshold based on $\mathrm{MOH}$ guidelines). Two accommodation types were included, i.e. low-rise housing (landed properties with one to three-story design) and high-rise housing (non-landed properties having four stories and above). We chose low-rise housing of terrace houses (Seksyen 2, Bandar Rinching, $2^{\circ} 55^{\prime} 50.4^{\prime \prime} \mathrm{N} 101^{\circ} 50^{\prime} 49.0^{\prime \prime} \mathrm{E}$ and Seksyen 5, Bandar Rinching, $2^{\circ} 55^{\prime} 50.9^{\prime \prime} \mathrm{N}$ $101^{\circ} 51^{\prime} 48.4^{\prime \prime E}$ ), and high-rise housing of five-story apartments (Pesona Apart-

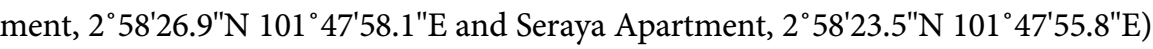
as our study sites. A distance of more than $500 \mathrm{~m}$ radius separated the unsprayed and treated areas, serving as a buffer zone. The four sites were randomly assigned to control (Seksyen 2 and Pesona Apartment) and treatment (Seksyen 5 and Seraya Apartment) groups.

The study was conducted between January 2014 and June 2015 with 62 weeks of data collection for entomological surveillance. The entomological surveillance was carried out during a four-week of baseline prior to the intervention and following three spray rounds in week 9/2014, week 33/2014 and week 5/2015. A spraying cycle of 4-months was carried out as recommended by the manufacturer for deltamethrin SC-PE (3 months residuality) and we extended another month for entomological surveillance. If there was a dengue incidence in the control and treated areas during the intervention period, the Ministry of Health $(\mathrm{MOH})$ guidelines shall be followed whereby activities under the mosquito control program that includes source reduction, larviciding, and space spraying will be conducted within $200 \mathrm{~m}$ radius of the infected house.

\subsection{Ethics Statement}

This study met with the ethical standard for Human Subject Research by the Medical Research and Ethics Committee (MREC). Study participants were informed on the objectives of the study by oral and information letter. Written informed consent forms were obtained from residents in both control and treated areas. Only around $2 \%$ of houses ( 7 out of 379 units) in the treated low-rise housing did not agree to participate in this study. Public engagement was conducted using banners, posters, and announcement brochures three days before the spraying activities were performed. 


\subsection{Insecticide Formulation and Application}

The insecticide used was polymer-enhanced deltamethrin (K-Othrine ${ }^{\circledR}$ Polyzone, Bayer Crop Science, Monheim am Rhein, Germany), which contains 62.5 $\mathrm{g} / \mathrm{L}$ deltamethrin as its active ingredient and formulated as a suspension concentrate (SC). The insecticide was prepared as recommended by the manufacturer and was sprayed using a calibrated hand compression sprayer (Hudson X-Pert, Chicago, IL, USA) with a flat fan nozzle (Teejet 8002, Spray Systems Co., Bessemer, AL, USA). Some of the external walls were not sheltered walls and were exposed to rainfalls. We decided to use a larger concentration $\left(30 \mathrm{mg} / \mathrm{m}^{2}\right)$ than the WHO-recommended dosage for IRS in malaria control $\left(20-25 \mathrm{mg} / \mathrm{m}^{2}\right)$ [22] to offset the amount of insecticide applied, withstanding the dry and wet season in Malaysia.

All accessible external walls in the house front yards and backyards were sprayed by trained staffs following procedures from WHO [28]. Safety procedures when spraying and handling of the insecticide were also followed [28]. The areas with aquarium or fish ponds, edible plants, surfaces that were near to the electric supply, water filter and water container were avoided. House owners were advised to keep their pets away during the spraying activities until the insecticide has dried completely. The percentage coverage of houses that have been sprayed in both types of accommodation was as described in Table 1. The coverage is defined by the total number of houses sprayed during a spray round divide by the total number of houses that were targeted [15]. The ORS coverage for terrace houses was not $100 \%$ due to inaccessibility to the houses since the homeowners were not at home at the time of spraying.

\subsection{Ovitrap Surveillance}

The number of larvae which translated to population densities of Ae aegypti and Ae. albopictus was assessed in the control and treated areas via ovitrap surveillance. We performed ovitrapping as described in Lee [29]. Ovitraps (300 ml black plastic containers, diameter $7.0 \mathrm{~cm}$ and height $9.0 \mathrm{~cm}$ ) filled with three-quarter of tap water along with the rough surface of the oviposition paddles (made from hardboard, approximately $10 \mathrm{~cm} \times 2.5 \mathrm{~cm} \times 0.3 \mathrm{~cm}$ ) facing upwards were placed at the ground level in both semi-indoor and outdoor environments. A total of 60 ovitraps and 40 ovitraps were placed in randomly selected houses in the low-rise

Table 1. The total number of houses and percentage coverage of houses that have been sprayed in the study areas.

\begin{tabular}{ccccc}
\hline Study site & $\begin{array}{c}\text { Seksyen 2 } \\
\text { (Control) }\end{array}$ & $\begin{array}{c}\text { Seksyen 5 } \\
\text { (Treated) }\end{array}$ & $\begin{array}{c}\text { Pesona Apt. } \\
\text { (Control) }\end{array}$ & $\begin{array}{c}\text { Seraya Apt. } \\
\text { (Treated) }\end{array}$ \\
\hline Total no. of houses & 389 & 379 & 100 & 100 \\
Percentage coverage in cycle 1 (\%) & NA & 72 & NA & 100 \\
Percentage coverage in cycle 2 (\%) & NA & 79 & NA & 100 \\
Percentage coverage in cycle 3 (\%) & NA & 55 & NA & 100 \\
\hline
\end{tabular}

${ }^{\star}$ NA-Not Applicable. 
and high-rise housing, respectively. The number of ovitraps was equally distributed between the semi-indoor and outdoor environments. Semi-indoor is defined as the area outside of the house units but shielded by the roof, e.g. the porch and hallway. The ovitraps were collected after seven days and immediately transported to the Institute for Medical Research (IMR) laboratory. New ovitraps were placed at the same time when exposed ovitraps were collected. Any disturbances to the exposed ovitraps, e.g. stolen or vandalized, ovitraps were tipped over, invasion by insects were recorded. The recovered ovitrap contents along with the paddle were poured into labelled plastic containers and separated according to the study sites and date of collection. Beef liver powder (Difco Laboratories, MD, USA) was added to the ovitrap contents. Fourth instar larvae were identified and separated according to species by using established taxonomy keys [30] [31] under a compound microscope (Nikon Eclipse ${ }^{\circledR}$ E100, Japan). Contents were examined for species identification until no newly emerged larvae were found.

\subsection{WHO Wall Deposit Bioassay}

The residual activity of deltamethrin SC-PE was evaluated following standard WHO wall deposit bioassay procedures with a few modifications [32]. The susceptible laboratory-reared strains of Ae. aegypti and Ae. albopictus from insectary of Medical Entomology Unit, IMR were used in this bioassay. Wall bioassay was conducted biweekly until week 16 in each cycle and was performed on the treated wall surfaces of approximately five percent of the total houses. The houses for the bioassays were randomly selected. Standard transparent plastic cones (internal diameter $8.5 \mathrm{~cm}$ and internal height $5.5 \mathrm{~cm}$ ) were fixed vertically onto the wall surfaces. Three bioassay cones, each containing 10 laboratory-reared mosquitoes (sucrose-fed, 2 - 5 days old) were prepared for each Aedes species. Mosquitoes were introduced gently into the bioassay cone using battery-operated aspirator. The aperture of the bioassay cone was plugged with a cotton ball. Mosquito knockdown was observed at the 1-minute interval for $30 \mathrm{~min}$. After the exposure, the mosquitoes were aspirated out and transferred into clean paper cups. The mosquitoes were fed with $10 \%(\mathrm{w} / \mathrm{v})$ sugar solution with the holding condition of $28^{\circ} \mathrm{C} \pm 2{ }^{\circ} \mathrm{C}$ and $75 \% \pm 10 \%$ relative humidity. The mortality was recorded at $24 \mathrm{~h}$ post-exposure. The classification of adult mosquitoes as knocked down or dead was as described by WHO [33].

\subsection{Meteorological Data}

We set up a weather station in each study site. Temperature and relative humidity were recorded using thermohygrometer Tinytag View 2 (TV-4500, Gemini Data Loggers Ltd., Sussex, UK) while rain gauge (RGR126N, Wireless Rain Gauge, Oregon Scientific, Oregon, US) was used to closely monitor rainfalls.

\subsection{Data Analysis}

Ovitrap index (OI) was calculated to assess the density of the Aedes population. 
OI is defined as the percentage of positive ovitraps per the number of ovitraps recovered. We also calculated the mean number of larvae in each positive ovitrap for each Aedes species. Since the data was not normally distributed, a non-parametric test of Mann-Whitney Test (equations described in 1, 2 and 3) was used to compare the OI and mean number of larvae between unsprayed control and treated sites.

$$
\begin{gathered}
T_{1}=n_{1} n_{2}+\frac{n_{1}\left(n_{1}+1\right)}{2}-S_{1} \\
T_{2}=n_{1} n_{2}+\frac{n_{2}\left(n_{2}+1\right)}{2}-S_{2} \\
T=\min \left(T_{1}, T_{2}\right)
\end{gathered}
$$

where $S_{1}=$ sum of the ranks assigned to the sample observations from Population $1, S_{2}=$ sum of the ranks assigned to the sample observations from Population 2, $n=$ number of individuals in the sample [34]. Bioassay results of $30 \mathrm{~min}$ knockdown (KD30) and mortality rates were calculated and analysed according to [35]. The association between time (months) and mortality were analysed using log-time probit regression [35] [36]. Comparisons of mean mortality between the types of housing were analysed using Mann-Whitney Test as described above. All analyses were performed using the Statistical Package for Social Sciences (SPSS) version 25.0 [37].

\section{Results}

\subsection{Surveillance of the Aedes Population}

The mean temperature recorded during the entire period studied was $29.29^{\circ} \mathrm{C} \pm$ $0.117^{\circ} \mathrm{C}\left(26.38^{\circ} \mathrm{C}-32.20^{\circ} \mathrm{C}\right)$ while the mean relative humidity was $73.45 \% \pm$ $1.004 \%(65.46 \%-81.44 \%)$. The mean precipitation recorded by the rain gauge was the highest during cycle 2 with $6.46 \pm 1.089 \mathrm{~mm}$ precipitations in the low-rise residences and $7.47 \pm 1.406 \mathrm{~mm}$ in the high-rise residences (Table 2). The rain amount was not statistically significant between the different housing types during the treatment period (Table 2).

Comparisons of the OI between unsprayed control and treated low-rise residences for semi-indoor ovitraps showed that there were no statistical differences ( $p$-value $>0.05$ ) during the treatment period (Table 3). Surprisingly, the OI at both control and treated sites decreased after spraying was conducted. Looking at the species-specific mean number of larvae per ovitrap, treated houses have unexpectedly higher mean number of $A$ e. aegypti larvae per ovitrap compared to unsprayed control (except in cycle 3). Interestingly, this contrasted with Ae. albopictus, which displayed a downward trend of larvae number per ovitrap with significant differences between treated houses and unsprayed control. This was reflected in the Ae. aegypti: Ae. albopictus ratio in which Ae. albopictus dominated during the baseline period and the predominant species changed to Ae. aegypti only in the treated area as seen in the treatment period (Table 3). Meanwhile, 
Table 2. Average rainfall for the low-rise and high-rise study areas during the treatment period.

\begin{tabular}{cccccc}
\hline \multirow{2}{*}{ Cycle } & \multicolumn{2}{c}{ Low-rise housing } & \multicolumn{2}{c}{ High-rise housing } & \multirow{2}{*}{$p$-value } \\
\cline { 2 - 5 } & Mean rainfall \pm SE & $95 \%$ CI & Mean rainfall \pm SE & $95 \%$ CI & \\
\hline Cycle 1 & $5.96 \pm 1.129$ & $(3.73,8.19)$ & $3.70 \pm 0.806$ & $(2.10,5.29)$ & 0.104 \\
Cycle 2 & $6.46 \pm 1.089$ & $(4.31,8.62)$ & $7.47 \pm 1.406$ & $(4.69,10.25)$ & 0.572 \\
Cycle 3 & $3.95 \pm 1.065$ & $(1.84,6.06)$ & $5.55 \pm 0.991$ & $(3.59,7.51)$ & 0.272 \\
\hline
\end{tabular}

Table 3. Comparisons of the ovitrap index and mean number of larvae between unsprayed control and treated low-rise residences for ovitraps placed in the semi-indoor environment.

\begin{tabular}{cccccc}
\hline Statistical analysis & Treatment & Baseline & Cycle 1 & Cycle 2 & Cycle 3 \\
\hline Ovitrap index (\%) & Seksyen 2 (control) & $85.00 \pm 5.10$ & $65.00 \pm 3.20$ & $65.00 \pm 3.10$ & $41.00 \pm 2.80$ \\
& Seksyen 5 (treated) & $70.00 \pm 6.20$ & $59.00 \pm 3.10$ & $71.00 \pm 2.70$ & $41.00 \pm 2.70$ \\
\hline$p$-value & 0.067 & 0.143 & 0.170 & 0.989 \\
\hline $\begin{array}{c}\text { Mean number of } A \text {. } \\
\text { aegypti larvae per }\end{array}$ & Seksyen 2 (control) & $4.85 \pm 2.286$ & $3.30 \pm 0.585$ & $1.45 \pm 0.172$ & $3.14 \pm 0.497$ \\
ovitrap & Seksyen 5 (treated) & $7.02 \pm 2.637$ & $5.28 \pm 0.646$ & $5.95 \pm 0.629$ & $2.74 \pm 0.430$ \\
\hline $\begin{array}{c}\text { Mean number of } \text { Ae. } \\
\text { albopictus larvae per }\end{array}$ & Seksyen 2 (control) & $28.23 \pm 4.492$ & $4.26 \pm 0.464$ & $5.28 \pm 0.559$ & $3.40 \pm 0.535$ \\
ovitrap & Seksyen 5 (treated) & $10.25 \pm 1.942$ & $2.24 \pm 0.308$ & $2.21 \pm 0.297$ & $1.84 \pm 0.299$ \\
\hline$p$-value & $0.000^{*}$ & $0.000^{*}$ & $0.000^{*}$ & $0.001^{*}$ \\
\hline $\begin{array}{c}\text { Ratio of Ae. aegypti: } \\
\text { Ae. albopictus }\end{array}$ & Seksyen 2 (control) & $1.00: 5.82$ & $1.00: 1.29$ & $1.00: 3.64$ & $1.00: 1.08$ \\
\hline
\end{tabular}

*indicates that there is a significant difference between control and treated site.

analyses of OI for ovitraps placed in the outdoor environment revealed that the treated houses have slightly lower OI values compared to unsprayed control (Table 4). As with the semi-indoor, we observed the same decreasing trend for Ae. albopictus where the differences were statistically significant $(p=0.000)$ between control and treated area (Table 4). Altogether, these results suggested that ORS with deltamethrin SC-PE was reducing Ae. albopictus larvae number, indicating a decreased of Ae. albopictus density in the low-rise residences.

The OI of semi-indoor ovitraps at treated high-rise residences declined after the first round of spraying with a significant difference between unsprayed control and treated site (Table 5). The OI subsequently increased in cycle 2 and decreased in cycle 3 (Table 5). As opposed to the low-rise housing, we found that the ORS is effective in reducing Ae. aegypti abundance as evident from the significantly lower number of Ae. aegypti larvae in the treated site than the unsprayed control (Table 5). This was supported by the Ae. aegypti: Ae. albopictus ratio that shifted to Ae. albopictus dominance during cycle 1 and 3. The ORS, unfortunately, did not seem to influence the number of Ae. albopictus larvae per 
Table 4. Comparisons of the ovitrap index and mean number of larvae between unsprayed control and treated low-rise residences for ovitraps placed in the outdoor environment.

\begin{tabular}{|c|c|c|c|c|c|}
\hline Statistical analysis & Treatment & Baseline & Cycle 1 & Cycle 2 & Cycle 3 \\
\hline \multirow{2}{*}{ Ovitrap index (\%) } & Seksyen 2 (control) & $72.00 \pm 5.50$ & $79.00 \pm 2.80$ & $75.00 \pm 2.80$ & $54.00 \pm 2.80$ \\
\hline & Seksyen 5 (treated) & $83.00 \pm 4.80$ & $66.00 \pm 3.50$ & $75.00 \pm 3.00$ & $47.00 \pm 3.00$ \\
\hline \multicolumn{2}{|c|}{$p$-value } & 0.142 & $0.004^{\star}$ & 0.920 & 0.107 \\
\hline Mean number of $A e$. & Seksyen 2 (control) & $4.93 \pm 1.423$ & $1.57 \pm 0.366$ & $0.49 \pm 0.112$ & $3.38 \pm 0.625$ \\
\hline ovitrap & Seksyen 5 (treated) & $4.06 \pm 0.964$ & $3.06 \pm 0.615$ & $8.52 \pm 0.938$ & $3.99 \pm 0.607$ \\
\hline \multicolumn{2}{|c|}{$p$-value } & 0.099 & $0.001^{*}$ & $0.000^{*}$ & $0.014^{*}$ \\
\hline $\begin{array}{l}\text { Mean number of } A e . \\
\text { albopictus larvae per }\end{array}$ & Seksyen 2 (control) & \multicolumn{2}{|c|}{$20.88 \pm 3.39810 .28 \pm 0.961$} & $10.42=$ & $9.35 \pm 0.878$ \\
\hline ovitrap & Seksyen 5 (treated) & $16.36 \pm 2.282$ & $4.89 \pm 0.650$ & $2.29 \pm 0.357$ & $1.61 \pm 0.303$ \\
\hline \multicolumn{2}{|c|}{$p$-value } & 0.849 & $0.000^{*}$ & $0.000^{*}$ & $0.000^{*}$ \\
\hline Ratio of Ae aegypti: & Seksyen 2 (control) & $1.00: 4.23$ & $1.00: 6.55$ & 1.0021 .27 & $1.00: 2.77$ \\
\hline Ae. albopictus & Seksyen 5 (treated) & $1.00: 4.03$ & $1.00: 1.59$ & $3.72: 1.00$ & $2.48: 1.00$ \\
\hline
\end{tabular}

${ }^{*}$ indicates that there is a significant difference between control and treated site.

Table 5. Comparisons of the ovitrap index and mean number of larvae between unsprayed control and treated high-rise residences for ovitraps placed in the semi-indoor environment.

\begin{tabular}{|c|c|c|c|c|c|}
\hline Statistical analysis & Treatment & Baseline & Cycle 1 & Cycle 2 & Cycle 3 \\
\hline \multirow{2}{*}{ Ovitrap index (\%) } & Pesona Apt. (control) & $55.00 \pm 6.50$ & $58.00 \pm 3.30$ & $61.00=$ & 36.00 \\
\hline & Seraya Apt. (treated) & $64.00 \pm 5.70$ & $47.00 \pm 3.40$ & $57.00 \pm 3.20$ & $49.00 \pm 2.60$ \\
\hline \multicolumn{2}{|c|}{$p$-value } & 0.301 & $0.022^{*}$ & 0.354 & $0.001^{*}$ \\
\hline $\begin{array}{l}\text { Mean number of } \\
A e, \text { gegyptilarvae }\end{array}$ & Peson & $6.93 \pm 2.069$ & $4.63 \pm 0$ & 5.28 & $3.72 \pm$ \\
\hline colo & Seraya Apt. (treated) & $8.32 \pm 2.460$ & $1.96 \pm 0.362$ & $2.98 \pm 0.480$ & $3.25 \pm 0.582$ \\
\hline \multicolumn{2}{|c|}{$p$-value } & 0.514 & $0.000^{*}$ & $0.000^{*}$ & 0.469 \\
\hline $\begin{array}{l}\text { Mean number of } \\
\text { Ae. albopictus }\end{array}$ & Pesona Apt. (control) & $1.58 \pm 0.598$ & $2.74 \pm 0.671$ & $0.63 \pm 0.119$ & $1.38 \pm 0.284$ \\
\hline larvae per ovitrap & Seraya Apt. (treated) & $1.33 \pm 0.388$ & $2.71 \pm 0.389$ & $1.46 \pm 0.230$ & $4.32 \pm 0.577$ \\
\hline \multicolumn{2}{|c|}{$p$-value } & 0.833 & 0.053 & $0.010^{*}$ & $0.001^{*}$ \\
\hline \multirow{2}{*}{$\begin{array}{c}\text { Ratio of Ae. aegypti: } \\
\text { Ae. albopictus }\end{array}$} & Pesona Apt. (control) & 4.39: 1.00 & 1.68: 1.00 & 8.38: 1.00 & $2.70: 1.00$ \\
\hline & Seraya Apt. (treated) & $6.26: 1.00$ & $1.00: 1.38$ & 2.04: 1.00 & $1.00: 1.33$ \\
\hline
\end{tabular}

*indicates that there is a significant difference between control and treated site.

ovitrap after spraying (Table 5). Both indices of OI and number of larvae for outdoor ovitraps in the high-rise residences did not differ considerably between unsprayed control and treated site (Table 6).

\subsection{Residual Bio-Efficacy of Deltamethrin SC-PE on Cement Walls}

Wall bioassays done on cement-painted walls in terrace houses displayed considerable variation in KD30 between the three spray cycles (Figure 1). The knockdown 
Table 6. Comparisons of the ovitrap index and mean number of larvae between unsprayed control and treated high-rise residences for ovitraps placed in the outdoor environment.

\begin{tabular}{|c|c|c|c|c|c|}
\hline Statistical analysis & Treatment & Baseline & Cycle 1 & Cycle 2 & Cycle 3 \\
\hline \multirow{2}{*}{ Ovitrap index (\%) } & Pesona & $100.00 \pm 0.00$ & $65.00 \pm 4.60$ & $80.00 \pm 3.00$ & $44.00 \pm$ \\
\hline & Seraya Apt. (treated) & $75.00 \pm 16.40$ & $61.00 \pm 4.70$ & $67.00 \pm 4.30$ & $46.00 \pm 2.80$ \\
\hline \multicolumn{2}{|c|}{$p$-value } & $0.023^{*}$ & 0.578 & $0.020^{*}$ & 0.692 \\
\hline $\begin{array}{l}\text { Mean number of } \\
\text { Ae. aegyptilarvae }\end{array}$ & Pesona Apt. (control) & $0.05 \pm 0.050$ & $2.97 \pm 0.942$ & $2.11 \pm 0.397$ & $2.80 \pm 0$ \\
\hline per ovitrap & Seraya Apt. (treated) & $8.38 \pm 5.653$ & $1.13 \pm 0.374$ & $0.57 \pm 0.1123$ & $2.70 \pm 0.490$ \\
\hline \multicolumn{2}{|c|}{$p$-value } & $0.004^{*}$ & 0.053 & $0.008^{\star}$ & 0.092 \\
\hline $\begin{array}{c}\text { Mean number of } \\
\text { Ae. albopictus }\end{array}$ & Pesona Apt. (control) & $36.75 \pm 6.928$ & $7.64 \pm 1.484$ & $8.25 \pm 0.915$ & $4.63 \pm 0.666$ \\
\hline larvae per ovitrap & Seraya Apt. (treated) & $13.75 \pm 8.217$ & $7.97 \pm 1.355$ & $7.72 \pm 0.836$ & $3.39 \pm 0.555$ \\
\hline \multicolumn{2}{|c|}{$p$-value } & $0.020^{*}$ & 0.715 & 0.821 & 0.164 \\
\hline Ratio of Ae. aegypti: & Pesona Apt. (control) & $1.00: 735.00$ & $1.00: 27.88$ & $1.00: 3.91$ & 1.00:1.65 \\
\hline Ae. albopictus & Seraya Apt. (treated) & $1.00: 13.75$ & $1.00: 7.05$ & $1.00: 13.54$ & $1.00: 1.26$ \\
\hline
\end{tabular}

*indicates that there is a significant difference between control and treated site.

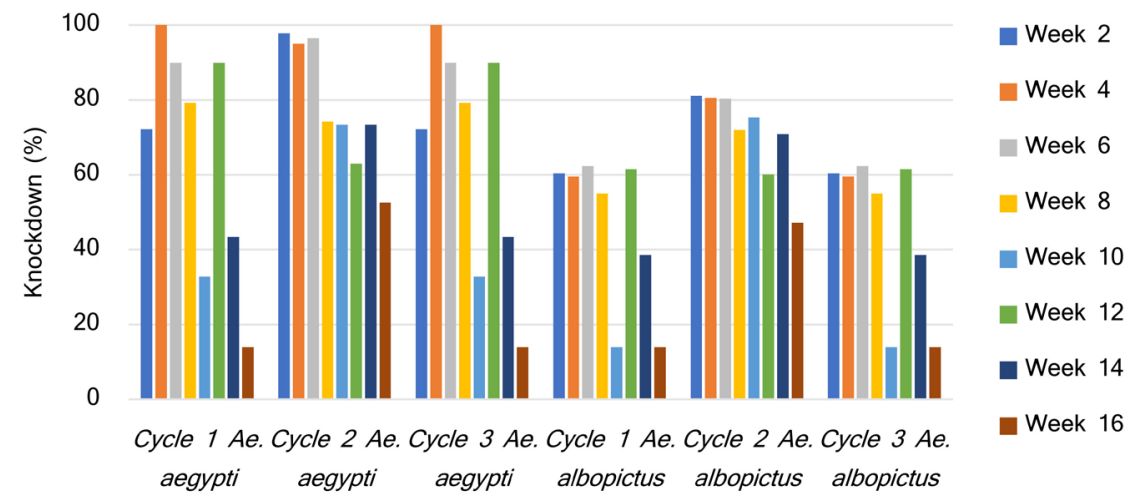

Figure 1. Percentage knockdown (KD30) of laboratory-reared Ae. aegypti and Ae. albopictus post-exposure to deltamethrin-treated walls in three rounds of spraying at treated low rise residences.

rates in cycle 1 and 3 remained above 80\% for 12 weeks in exposed Ae aegypti, while for 6 weeks in cycle 2 (Figure 1). The KD30 values, however, did not appear to be reflected in the percentage mortality where cycle 2 exhibited high mortality rate (above the WHO $80 \%$ mortality threshold) until week 14 for both Aedes spp., as opposed to cycle 1 and 3 that lasted until week 12 (Figure 2). Overall, there was a downward trend of KD30 and mortality from week 2 to week 16, suggesting that the residual bio-efficacy of deltamethrin SC-PE was reducing over time.

Like low-rise housing type, variation in knockdown rates was also reported in the high-rise residences. The overall trend showed that same descending trend over time, with cycle 3 produced higher KD30 for both Aedes spp. compared to the other cycles (Figure 3 ). Percentage knockdown remained high (>80\%) until week 16 as seen in cycle 3 for Ae. aegypti. For Ae. albopictus, KD30 remained 


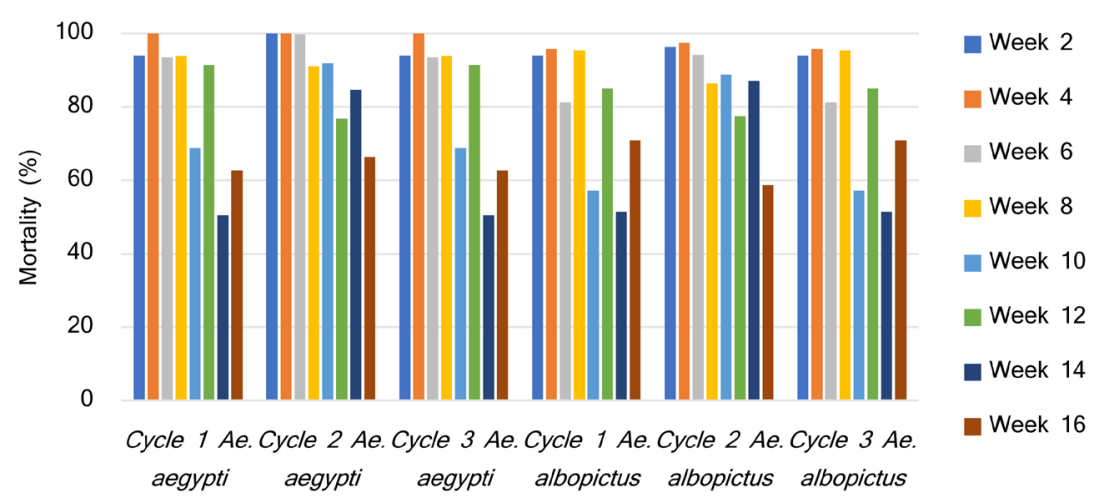

Figure 2. Percentage mortality ( $24 \mathrm{~h}$ ) of laboratory-reared Ae. aegypti and Ae. albopictus post-exposure to deltamethrin-treated walls in three rounds of spraying at treated low-rise residences.

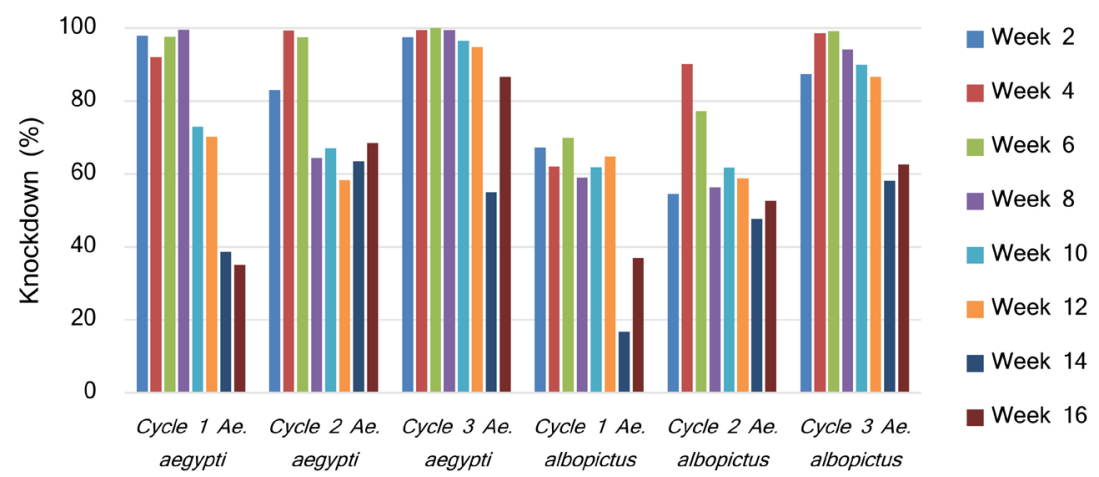

Figure 3. Percentage knockdown (KD30) of laboratory-reared Ae. aegypti and Ae. albopictus after exposure to deltamethrin-treated walls in three rounds of spraying at high-rise residences.

above $80 \%$ until week 12 in cycle 3 (Figure 3 ). There were very high mortality rates (above $80 \%$ threshold) observed for both Aedes spp. in cycle 3, which lasted until week 16 (Figure 4). Looking at the mortality rates between the different accommodation types suggests that deltamethrin SC-PE has a higher residual efficacy in eliminating Aedes laboratory strains in the apartment ( $>80 \%$ for 16 weeks) compared to terrace houses ( $>80 \%$ for 14 weeks).

The time (months) needed to eliminate $50 \%$ of the Aedes population $\left(\mathrm{LT}_{50}\right)$ and $90 \%$ of the population $\left(\mathrm{LT}_{90}\right)$ of exposed mosquito was analyzed using log-time probit regression. The results of probit analysis revealed that Ae. aegypti exposed to deltamethrin SC-PE in terrace houses exhibited $\mathrm{LT}_{50}$ of 22.32 months and $\mathrm{LT}_{90}$ of 6.61 months (Table 6). In comparison, longer periods of $\mathrm{LT}_{50}$ of 34.44 months and $\mathrm{LT}_{90}$ of 9.52 months were seen for Ae aegypti in the treated apartment (Table 7), suggesting that the residual bio-efficacy in apartment exceeded that of terrace houses. Ae. albopictus followed the same trend, at which treated apartment displayed a longer period of $\mathrm{LT}_{90}$ (6.26 months) compared to terrace houses $\left(\mathrm{LT}_{90}=4.49\right.$ months) (Table 7$)$. Post-hoc analyses supported probit regression results demonstrating that treated apartment has higher means of mortality rate for both Aedes spp. in comparison to treated terrace houses (Table 8). 


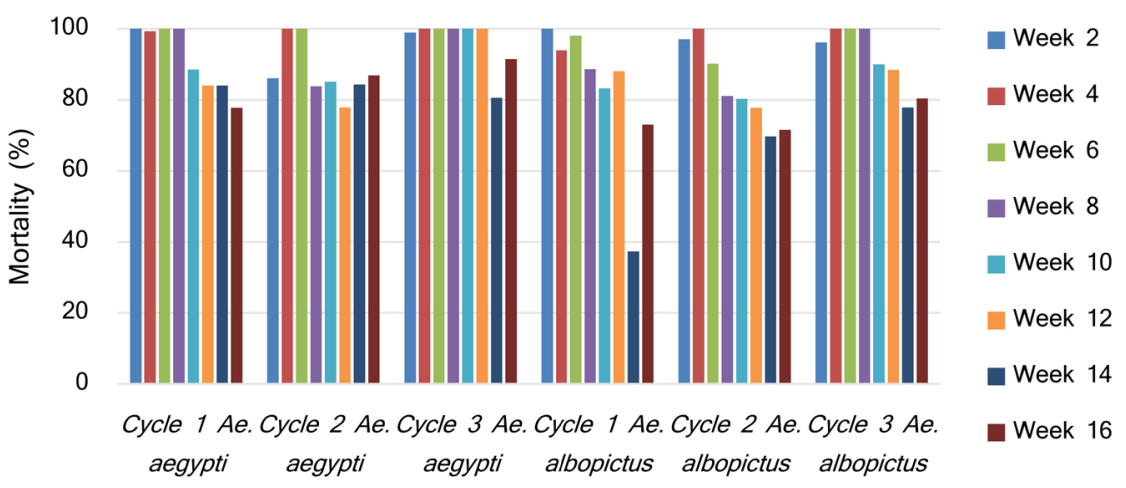

Figure 4. Percentage mortality ( $24 \mathrm{~h}$ ) of laboratory-reared Ae. aegypti and Ae. albopictus after exposure to deltamethrin-treated walls in three rounds of spraying at high-rise residences.

Table 7. Probit mortality per log time (months) regression analyses for each accommodation type from which $\mathrm{LT}_{50}$ and $\mathrm{LT}_{90}$ were estimated. The analysis was conducted using SPSS Statistics.

\begin{tabular}{ccccc}
\hline \multirow{2}{*}{ Housing type } & Aedes species & \multicolumn{2}{c}{ Lethal time, $\mathrm{LT}$ (months) } & $\begin{array}{c}\text { Regression } \\
\text { coefficient } \pm \mathrm{SE}\end{array}$ \\
\cline { 3 - 4 } & \multirow{2}{*}{ Low-rise } & $\mathrm{LT}_{50}$ & $\mathrm{LT}_{90}$ & \\
& Ae. aegypti & 22.32 & 6.61 & $3.269 \pm 0.163$ \\
& & $(17.10-37.68)$ & $(5.00-7.84)$ & \\
& Ae. albopictus & 36.66 & 4.49 & $2.197 \pm 0.112$ \\
& & $(20.04-288.31)$ & $(1.75-6.39)$ & \\
High-rise & Ae. aegypti & 34.44 & 9.52 & $3.526 \pm 0.220$ \\
& & $(20.90-289.66)$ & $(5.99-12.62)$ & \\
& Ae. albopictus & 23.67 & 6.26 & $3.048 \pm 0.160$ \\
& & $(16.87-55.75)$ & $(3.66-8.05)$ & \\
\hline
\end{tabular}

Table 8. Comparisons of the mean mortality for Aedes populations between different types of housing were analyzed using Mann-Whitney Test in SPSS Statistics.

\begin{tabular}{ccccc}
\hline Aedes species & Housing type & Mean \pm SE & $95 \% \mathrm{CI}$ & $p$-value \\
\hline \multirow{2}{*}{ Ae. aegypti } & Low-rise & $89.2 \pm 0.80$ & $(87.6,90.8)$ & 0.007 \\
& High-rise & $94.1 \pm 0.69$ & $(92.8,95.5)$ & \\
\multirow{2}{*}{ Ae. albopictus } & Low-rise & $87.0 \pm 0.85$ & $(85.3,88.6)$ & 0.170 \\
& High-rise & $87.3 \pm 0.87$ & $(85.6,89.0)$ & \\
\hline
\end{tabular}

\section{Discussion}

This was the first field study that evaluated the efficacy of deltamethrin SC-PE in an ORS intervention. The findings of this study provide initial evidence on its potential utilization as part of the national dengue vector control program. ORS can potentially be used during dengue outbreaks acting as an alternative to ULV or thermal fogging that only has transient residual activity. The study demonstrated that ORS had entomological impacts, with significant reductions in population densities of Ae. aegypti or Ae. albopictus-depending on the type of ac- 
commodation, up to 4 months of post-spraying. The results of this study contrasted with a previous ORS study performed using deltamethrin WG which did not show any effect on the number of larvae in the sprayed area [38]. The study, however, was only carried out in a short period of 12 weeks. Our study used the improved formulation of deltamethrin and showed an impact on reducing Aedes population size.

The initial dominance of Ae. albopictus during the baseline in the semi-indoor and outdoor environments in low-rise residences could be elucidated through its behavior. It is worthwhile mentioning that in terrace houses, semi-indoor ovitraps were placed outside of houses, in which they were partly shielded by roofs. Ae. albopictus is largely considered as exophilic (outdoor resting) and exophagic (feeds outdoor), which breeds in natural habitats such as tree holes as well as man-made containers [39] [40]. Moderate- or high-density vegetation such as shrubs and trees that were spotted in the terrace house yards are the preferred habitats for Ae. albopictus. Vector studies in other locations in Malaysia have also discovered that Ae. albopictus was the dominant species in the outdoor environment [41] [42]. ORS using deltamethrin SC-PE appeared to produce a quantifiable impact on Ae. albopictus population size, but not on Ae aegypti, depicted from the significant reduction in the number of larvae and the shifting of dominance to Ae. aegypti at post-spraying. We think that ORS may have affected Ae. aegypti abundance but the method that we used was not sensitive enough to capture this impact since Ae. aegypti was not the dominant species in this type of housing. Resistance to deltamethrin seemed unlikely since standard WHO susceptibility assay performed using another pyrethroid insecticide of permethrin $0.75 \%$ against wild Ae aegypti in the treated area exhibited $100 \%$ mortality [43].

In the high-rise housing type, Ae. aegypti dominated in the semi-indoor environment during the baseline. The apartment semi-indoor was mostly sheltered walls that were nonetheless considered as indoor, and so the initial abundance of Ae. aegypti was highly anticipated due to its behavior. Ae. aegypti is primarily known as endophilic species (indoor resting), endophagy (feeds indoors) and prefers indoor artificial containers for breeding [26] [27]. We discovered that the number of $A$ e. aegypti population size decreased in the treated site after spraying and that the dominance has changed to Ae. albopictus in cycle 1 and 3, suggesting ORS was effective in eliminating Ae. aegypti. ORS did not seem to have an effect on the outdoor environment. A likely explanation was that the outdoor ovitraps were placed quite far from the sprayed walls, offering a less residual effect of the ORS.

Several external factors could have influenced the OI and the number of larvae per ovitrap in both control and treated sites. A likely factor was the dengue control and preventive actions performed by the Health District Office if there is a reported dengue case in the areas, which might influence the Aedes population. Another factor that should be taken into consideration was the rainy season in Malaysia. During the second cycle, we observed an increase in OI in both types 
of accommodation. The second cycle coincided with the rainy season of the inter-monsoon period (October-November), in which the rainfall was higher than the rest of the cycles. Additionally, results should be interpreted with caution because measures of ovitraps in the study did not correlate with indoor adult abundance. The evaluation of efficacy was based solely on semi-indoor and outdoor ovitrap collection, which did not consider the probability of indoor cryptic breeding sites such as the toilet tanks [44].

The high percentage mortality of laboratory-reared strains of Ae. aegypti and Ae. albopictus (above the WHO 80\% mortality threshold) was probably stemmed from the correct formulation of deltamethrin SC-PE used on the painted cement walls. The SC formulation was found to be more suitable on cement wall surfaces than another deltamethrin formulation of WG in a recent study [23]. Furthermore, the higher mean of mortality for both Aedes spp. in the high-rise residences in comparison to the low-rise residences was most likely, in part, due to environmental influences. Since the walls in terrace houses were exposed to rainfalls and sunlight, the rate of insecticide removal from the wall surfaces of terrace houses was higher than the sheltered walls in the apartment. Besides, there appeared to be a gradual accumulation of insecticide on the wall going from spray cycle 1 to cycle 3 , influencing the knockdown and mortality rates. It was observed that cycle 3 exhibited mortality of $>80 \%$ until week 16 for both Aedes spp. in the high-rise residences in comparison to cycle 1 which lasted until week 14 for Ae. aegypti and week 12 for Ae. albopictus.

The impact of vector control on reducing Aedes density is well established [45], but the evidence of the efficacy of vector control in reducing the incidence of dengue is limited. Indeed, a key limitation was that our study was not designed to detect such a relationship. To our knowledge, only a few studies have reported a positive relationship between mosquitos abundance and the number of dengue cases [46] [47]. Interestingly, Guo et al. [47] found that the increase in Ae. albopictus abundance with a lag time of one month is associated with dengue outbreak in the region. In their critical review, Wilson et al. [48] reported that shortcomings in the study design, conduct, analysis, and reporting of vector control studies are the common factors that limit the assessment of the efficacy of vector control programs on the epidemiological outcomes i.e. reduction of human cases. Recommendations on the design and conduct of vector-control studies that would provide evidence of such interventions on the epidemiology of the targeted vector-borne disease have been published recently [48] [49], which could be applied in the future studies.

Thinking beyond dengue control, the recent outbreaks of Zika virus that followed West Nile virus (emerged in 1999) and Chikungunya (emerged in 2013) underline challenges in the fight against mosquito-borne diseases and their huge public health implication. Vector-borne diseases accounted for more than $10 \%$ of the burden of infectious diseases around the world [50]. To date, no vaccines have been developed so far against these diseases. As a consequence, even in the presence of some vaccines, vector control would still have beneficial effects by 
enhancing vaccination programs to further reduce human cases and by playing as cross-disease vector control programs. Programmatic projects such as the Partnership for Dengue Control (PDC) may be useful to show the full impact of such integrated programs. The partnership was established in 2013 and is a global consortium of international health agencies and dengue experts to facilitate this new paradigm by providing expert guidance to dengue-endemic countries for dengue management and to combine best practices and facilitate information on the design of improved and innovative disease-prevention strategies [51].

\section{Conclusion}

In summary, we report on the initial evidence of deltamethrin SC-PE in reducing Aedes populations in the low-rise and high-rise housings. This study was useful in providing an estimation of the performance of deltamethrin SC-PE in ORS. We suggested that the ORS needs to be completed in three spray rounds of a four-month cycle to optimize its efficacy. Perhaps more well-designed randomized controlled studies with both entomological and epidemiological endpoints are warranted to better understand the true entomological effects of ORS and its impact on dengue incidence. Our results showed that ORS is a promising tool in the dengue vector control and like IRS in malaria control, it is a powerful and effective method if conducted correctly. However, similar to the IRS, several factors should be considered when conducting ORS. These include the requirement for skillful staffs to ensure uniform application of the insecticide, household's accessibility, and suitability of wall surfaces and insecticides. This study did develop excellent community trust and support that could help pave the way for further trials aiming at evaluating the impact of ORS on the incidence of vector-borne diseases such as dengue, chikungunya, and Zika.

\section{Acknowledgements}

The authors thank the Director General of Health, Malaysia for his permission to publish this article, Director of IMR, Kuala Lumpur for continuous support, and Bayer Co. (Malaysia) for their support by providing training to the staffs. Many thanks are owed to the Hulu Langat District Health Officer, staffs of Hulu Langat Health District Office and staffs of the Medical Entomology Unit, IMR for the help in the field. This research was supported by the National Institutes of Health Grant (NMRR-13-921-17915) from the Ministry of Health, Malaysia.

\section{Conflicts of Interest}

The authors declared that there are no potential conflicts of interest with respect to the research, authorship, and/or publication of this article.

\section{References}

[1] Bhatt, S., Gething, P.W., Brady, O.J., Messina, J.P., Farlow, A.W., et al. (2013) The 
Global Distribution and Burden of Dengue. Nature, 496, 504-507. https://doi.org/10.1038/nature12060

[2] Brady, O.J., Gething, P.W., Bhatt, S., Messina, J.P., Brownstein, J.S., et al. (2012) Refining the Global Spatial Limits of Dengue Virus Transmission by Evidence-Based Consensus. PLoS Neglected Tropical Diseases, 6, e1760.

https://doi.org/10.1371/journal.pntd.0001760 https://journals.plos.org/plosntds/article?id=10.1371/journal.pntd.0001760

[3] Yusoff, H.M. (2008) National Dengue Programme in Malaysia. World Health Organization-Western Pacific Region, 83-86.

[4] Mohd-Zaki, A.H., Brett, J., Ismail, E. and L’Azou, M. (2014) Epidemiology of Dengue Disease in Malaysia (2000-2012): A Systematic Literature Review. PLoS Neglected Tropical Diseases, 8, e3159. https://doi.org/10.1371/journal.pntd.0003159

[5] Cheah, W.K., Ng, K.S., Marzilawati, A.R. and Lum, L.C. (2014) A Review of Dengue Research in Malaysia. Medical Journal of Malaysia, 69, 59-67.

[6] Schliessmann, D.J. and Calheiros, L.B. (1974) A Review of the Status of Yellow Fever and Aedes Aegypti Eradication Programs in The Americas. Mosquito News, 34, $1-9$.

[7] PAHO (1997) The Feasibility of Eradicating Aedes aegypti in the Americas. Revista Panamericana de Salud Pública, 1, 68-72. https://doi.org/10.1590/S1020-49891997000100023

[8] Kouri, G., Guzman, M.G., Valdes, L., Carbonel, I., del Rosario, D., et al. (1998) Reemergence of Dengue in Cuba:A 1997 Epidemic in Santiago de Cuba. Emerging Infectious Diseases, 4, 89-92. https://doi.org/10.3201/eid0401.980111

[9] Guzman, M.G., Alvarez, M., Rodriguez, R., Rosario, D., Vazquez, S., et al. (1999) Fatal Dengue Hemorrhagic Fever in Cuba, 1997. International Journal of Infectious Disease, 3, 130-135. https://doi.org/10.1016/S1201-9712(99)90033-4

[10] Ooi, E.E., Goh, K.T. and Gubler, D.J. (2006) Dengue Prevention and 35 Years of Vector Control in Singapore. Emerging Infectious Diseases, 12, 887-893. https://doi.org/10.3201/eid1206.051210

[11] Horstick, O., Tozan, Y. and Wilder-Smith, A. (2015) Reviewing Dengue:Still a Neglected Tropical Disease? PLoS Neglected Tropical Diseases, 9, e0003632. https://doi.org/10.1371/journal.pntd.0003632

[12] Gubler, D.J. (2012) The Economic Burden of Dengue. The American Journal of Tropical Medicine and Hygiene, 86, 743-744. https://doi.org/10.4269/ajtmh.2012.12-0157

[13] Gubler, D. (2013) Prevention and Control of Aedes aegypti-Borne Diseases:Lesson Learned from Past Successes and Failures. Asia-Pacific Journal of Molecular Biology and Biotechnology, 19, 111-114.

[14] Achee, N.L., Gould, F., Perkins, T.A., Reiner, R.C., Morrison, A.C., et al. (2015) A Critical Assessment of Vector Control for Dengue Prevention. PLoS Neglected Tropical Diseases, 9, e0003655. https://doi.org/10.1371/journal.pntd.0003655

[15] WHO (2015) Indoor Residual Spraying:An Operational Manual for Indoor Residual Spraying (IRS) for Malaria Transmission Control and Elimination. Second Edition, $1-134$.

[16] Carter, R. and Mendis, K.N. (2002) Evolutionary and Historical Aspects of the Burden of Malaria. Clinical Microbiology Reviews, 15, 564-594. https://doi.org/10.1128/CMR.15.4.564-594.2002

[17] Tanner, M. and de Savigny, D. (2008) Malaria Eradication Back on the Table. Bulle- 
tin of the World Health Organization, 86, 82-82. https://doi.org/10.2471/BLT.07.050633

[18] Wernsdorfer, W.H. (1980) The Importance of Malaria in the World. Academic Press, Inc., New York, London.

[19] Paredes-Esquivel, C., Lenhart, A., del Rio, R., Leza, M.M., Estrugo, M., et al. (2016) The Impact of Indoor Residual Spraying of Deltamethrin on Dengue Vector Populations in the Peruvian Amazon. Acta Tropica, 154, 139-144. https://doi.org/10.1016/j.actatropica.2015.10.020

[20] Vazquez-Prokopec, G.M., Medina-Barreiro, A., Che-Mendoza, A., Dzul-Manzanilla, F., Correa-Morales, F., et al. (2017) Deltamethrin Resistance in Aedes aegypti Results in Treatment Failure in Merida, Mexico. PLoS Neglected Tropical Diseases, 11, e0005656. https://doi.org/10.1371/journal.pntd.0005656 https://journals.plos.org/plosntds/article?id=10.1371/journal.pntd.0005656

[21] Vazquez-Prokopec, G.M., Montgomery, B.L., Horne, P., Clennon, J.A. and Ritchie, S.A. (2017) Combining Contact Tracing with Targeted Indoor Residual Spraying Significantly Reduces Dengue Transmission. Science Advances, 3, e1602024.

https://doi.org/10.1126/sciadv.1602024

https://advances.sciencemag.org/content/3/2/e1602024.full

[22] WHO (2015) WHO Recommended Insecticides for Indoor Residual Spraying Against Malaria Vectors. 1.

[23] Dunford, J.C., Estep, A.S., Waits, C.M., Richardson, A.G., Hoel, D.F., et al. (2018) Evaluation of the Long-Term Efficacy of K-Othrine PolyZone on Three Surfaces Against Laboratory Reared Anopheles gambiae in Semi-Field Conditions. Malaria Journal, 17, 94. https://doi.org/10.1186/s12936-018-2239-Z

[24] Kijlstra, J., Nentwig, G., Rosenfeldt, F., Sonneck, R., Reid, B., et al. (2014) A Polymer Enhanced Formulation to Prolong the Effectiveness of Surface Sprays. Proceedings of the 8 th International Conference on Urban Pests, Zurich, 383-388.

[25] Oxborough, R.M., Kitau, J., Jones, R., Mosha, F.W. and Rowland, M.W. (2014) Experimental Hut and Bioassay Evaluation of the Residual Activity of a Polymer-Enhanced Suspension Concentrate (SC-PE) Formulation of Deltamethrin for IRS Use in the Control of Anopheles arabiensis. Parasites \& Vectors, 7, 454. https://doi.org/10.1186/s13071-014-0454-1

[26] Dzul-Manzanilla, F., Ibarra-Lopez, J., Bibiano Marin, W., Martini-Jaimes, A., Leyva, J.T., et al. (2017) Indoor Resting Behavior of Aedes aegypti (Diptera:Culicidae) in Acapulco, Mexico. Journal of Medical Entomology, 54, 501-504. https://doi.org/10.1093/jme/tjw203

[27] Chadee, D.D. (2013) Resting Behaviour of Aedes aegypti in Trinidad:With Evidence for the Re-Introduction of Indoor Residual Spraying (IRS) for Dengue Control. Parasites \& Vectors, 6, 255. https://doi.org/10.1186/1756-3305-6-255

[28] WHO (2007) Manual for Indoor Residual Spraying Application of Residual Sprays for Vector Control. Third Edition, 1-43.

[29] Lee, H.L. (1992) Aedes Ovitrap and Larval Survey in Several Suburban Communities in Selangor, Malaysia. Mosquito-Borne Diseases Bulletin, 9, 9-15.

[30] Pratt, H.D., Stojanovich, C.J. and Magennis, N.J. (1964) Workbook on Identification of Aedes aegypti Larvae. U.S. Department of Health, Education and Welfare, Atlanta.

[31] Parija, S. (2014) Illustrated Keys:Some Mosquitoes of Peninsula Malaysia. Tropical Parasitology, 4, 70. https://doi.org/10.4103/2229-5070.129139 
[32] WHO (2013) Guidelines for Laboratory and Field-Testing of Long-Lasting Insecticidal Nets. 1-89.

[33] WHOPES (2012) Report of the Fifteenth WHOPES Working Group Meeting:WHO/HQ, Geneva, 18-22 June 2012:Review of Olyset Plus, Interceptor LN, Malathion 440 EW, Vectobac GR. 1-99.

[34] Haron, H. (2010) Understanding Statistics with SPSS:A Friendly Approach. University Publication Centre, Universiti Teknologi MARA, Shah Alam.

[35] WHO (2006) Guidelines for Testing Mosquito Adulticides for Indoor Residual Spraying and Treatment of Mosquito Nets. 1-60.

[36] Finney, D.J. (1971) Probit Analysis. Cambridge University Press, New York.

[37] IBM C.R. (2017) IBM SPSS Statistics for Windows, Version 25.0. IBM Corp., Armonk.

[38] Rozilawati, H., Lee, H.L., Mohd Masri, S., Mohd Noor, I. and Rosman, S. (2005) Field Bioefficacy of Deltamethrin Residual Spraying against Dengue Vectors. Tropical Biomedicine, 22, 143-148.

[39] Estrada-Franco, J.G. and Craig, G.B. (1995) Biology, Disease Relationships, and Control of Aedes albopictus. Pan American Health Organization, Washington DC.

[40] Paupy, C., Delatte, H., Bagny, L., Corbel, V. and Fontenille, D. (2009) Aedes albopictus, an Arbovirus Vector:From the Darkness to the Light. Microbes and Infection, 11, 1177-1185. https://doi.org/10.1016/j.micinf.2009.05.005

[41] Ahmad, N.A., Arif Abd Karim, M., Wasi Ahmad, N. and Hanlim, L. (2018) Ovitrap Surveillance of Aedes aegypti and Aedes albopictus in Dengue Endemic Areas in Keramat and Shah Alam, Selangor in 2016. International Medical Journal Malaysia, 17, 59-64.

[42] Lim, K.W., Sit, N.W., Norzahira, R., Sing, K.W., Wong, H.M., et al. (2010) Dengue Vector Surveillance in Insular Settlements of Pulau Ketam, Selangor, Malaysia. Tropical Biomedicine, 27, 185-192.

[43] Rasli, R., Hanlim, L., Nazni, W.A., Hamid, A.N., Ali, R., et al. (2017) Pyrethroid Resistance Status of Aedes (Stegomyia) Aegypti (Linneaus) from Dengue Endemic Areas in Peninsular Malaysia. International Medical Journal Malaysia, 16, 73-78.

[44] Dieng, H., Saifur, R.G.M., Ahmad, A.H., Salmah, M.R.C., Aziz, A.T., et al. (2012) Unusual Developing Sites of Dengue Vectors and Potential Epidemiological Implications. Asian Pacific Journal of Tropical Biomedicine, 2, 228-232. https://doi.org/10.1016/S2221-1691(12)60047-1

[45] Erlanger, T.E., Keiser, J. and Utzinger, J. (2008) Effect of Dengue Vector Control Interventions on Entomological Parameters in Developing Countries:A Systematic Review and Meta-Analysis. Medical and Veterinary Entomology, 22, 203-221. https://doi.org/10.1111/j.1365-2915.2008.00740.x

[46] Barrera, R., Amador, M. and MacKay, A.J. (2011) Population Dynamics of Aedes aegypti and Dengue as Influenced by Weather and Human Behavior in San Juan, Puerto Rico. PLoS Neglected Tropical Diseases, 5, e1378. https://doi.org/10.1371/journal.pntd.0001378

[47] Guo, S., Ling, F., Hou, J., Wang, J., Fu, G., et al. (2014) Mosquito Surveillance Revealed Lagged Effects of Mosquito Abundance on Mosquito-Borne Disease Transmission:A Retrospective Study in Zhejiang, China. PLoS ONE, 9, e112975.

https://doi.org/10.1371/journal.pone.0112975

https://journals.plos.org/plosone/article/comments?id=10.1371/journal.pone.01129

$\underline{75}$ 
[48] Wilson, A.L., Boelaert, M., Kleinschmidt, I., Pinder, M., Scott, T.W., et al. (2015) Evidence-Based Vector Control? Improving the Quality of Vector Control Trials. Trends in Parasitology, 31, 380-390. https://doi.org/10.1016/j.pt.2015.04.015

[49] Reiner, R.C., Achee, N., Barrera, R., Burkot, T.R., Chadee, D.D., et al. (2016) Quantifying the Epidemiological Impact of Vector Control on Dengue. PLoS Neglected Tropical Diseases, 10, e0004588. https://doi.org/10.1371/journal.pntd.0004588

[50] Golding, N., Wilson, A.L., Moyes, C.L., Cano, J., Pigott, D.M., et al. (2015) Integrating Vector Control across Diseases. BMC Medicine, 13, 249. https://doi.org/10.1186/s12916-015-0491-4

[51] Gubler, D. (2015) The Partnership for Dengue Control-A New Global Alliance for the Prevention and Control of Dengue. Vaccine, 33, 1233.

https://doi.org/10.1016/j.vaccine.2015.01.002 